\title{
DOES IT ADD UP? PROFESSIONAL DEVELOPMENT FOR ELEMENTARY MATH TEACHERS
}

\author{
Susan Peet, Deborah Wooldridge, Cynthia Bertelsen, \& Ken Newbury \\ Bowling Green State University (USA)
}

\begin{abstract}
A two-year, quasi-experimental design research study evaluated the impact of professional development on teachers' knowledge/beliefs and behaviors related to mathematics instruction in elementary settings. 44 teachers (22 in control group and 22 in treatment group) completed the Teacher Knowledge Assessment System (TKAS), an online system for administering the Learning Mathematics for Teaching (LMT) assessment that measures teachers' basic mathematical knowledge and teachers' pedagogical content knowledge in mathematics (Hill, Schilling, \& Ball, 2004; Phelps, 2011). Teachers in the treatment condition showed significantly greater improvement in their knowledge of mathematics than did those in the control group. The treatment group also showed significantly more growth on LMT/TKAS test than did the control group. Findings from the second-year evaluation of changes in teachers' knowledge and beliefs about elementary mathematics instruction show that the professional development did improve teacher mathematical knowledge and beliefs relevant to improving mathematics instruction.
\end{abstract}

Keywords: Professional development, teachers, mathematics instruction, elementary education.

\section{Introduction}

Teaching excellence in elementary school mathematics is urgently needed (D'Ambrosio, Boone, \& Harkness, 2004). Children who acquire strong mathematics skills in elementary school are likely to be able to excel in higher-order math concepts at later points in education (Telese, 2012). This study investigated the impact on elementary teachers' knowledge and beliefs about mathematics education professional development opportunity. The impact of professional development on teachers has been established in prior research (Farmer, Gerretson, \& Lassak (2003). Teachers participated in a professional development program known as Math Strong.

\section{Design and objectives}

A two-year, quasi-experimental design evaluated the impact of professional development on teachers' knowledge/beliefs and behaviors related to mathematics instruction in elementary settings. Specifically, the study examined the following questions:

1. Is professional development training for elementary teachers using the Math Strong Program significantly related to teachers' mathematical knowledge and skills about two subscales (Number, Concepts and Operations, TKAS-NCOP and Patterns, Functions and Algebra, TKAS-PFAS) of the Teacher Knowledge Assessment System (TKAS)?

2. Is professional development training for elementary teachers using the Math Strong Program significantly related to teachers' beliefs about improving mathematics instruction as measured on the Teacher Knowledge Assessment System (TKAS)?

\section{Methods}

Forty-four teachers were assigned to either a control $(n=22)$ or treatment $(n=22)$ group. Teachers in the treatment group completed the Teacher Knowledge Assessment System (TKAS) online tool. TKAS measures teachers' basic mathematical knowledge and teachers' pedagogical content knowledge in mathematics (Hill, Schilling, \& Ball, 2004; Phelps, 2011). The scales of the tool consist of Number, Concepts and Operations subscale (TKAS-NCOP) and Patterns, Functions, and Algebra (TKAS-PFAS). 


\section{Discussion}

Number, Concepts and Operations Subscale - A 2 (Condition: Treatment, Control) x 2 (Time: Pretest, Post-test) ANOVA of the TKAS-NCOP scores, with time as a repeated measure did not find significant main effects of either Time $(\mathrm{F}(1,42)=.658$, ns., $\eta 2=.005)$, or Condition $(\mathrm{F}(1,42)=1.31$, ns., $\eta 2=.030)$, but there was a significant Condition $x$ TIME interaction $(F(1,42)=8.81, p<.01, \eta 2=.173)$. The chart below shows that treatment group teachers had lower scores than the control group at the pretest; at posttest, the treatment group scores were slightly higher than the control group.

Table 1. Change in TKAS-NCOP scores in treatment and control groups pre-and post-professional development training.

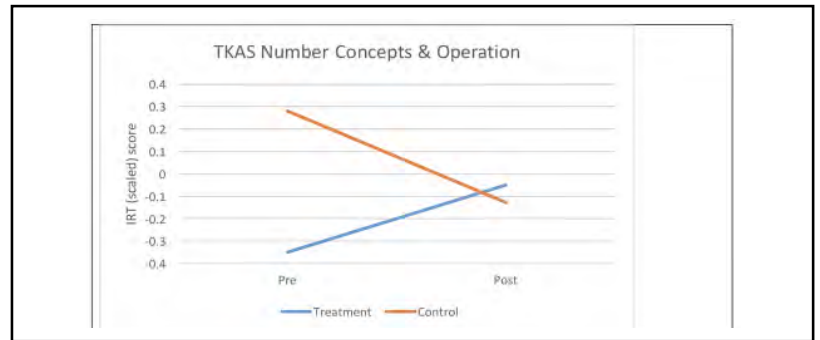

Patterns, Functions, and Algebra. A 2 (Condition: Treatment, Control) x 2 (Time: Pretest, Post-test) ANOVA of the TKAS-PFA scores, with time as a repeated measure did not find significant main effects of either Time $(\mathrm{F}(1,41)=.422$, ns., $\eta 2=.010)$, or Condition $(\mathrm{F}(1,42)=.278$, ns., $\eta 2=.0070)$, but there was a significant Condition $x$ TIME interaction $(F(1,42)=5.445, p<.05, \eta 2=.117)$. Like with the number, concepts and operations subscale, the treatment group teachers had lower scores than the control group at the pretest; at post-test the treatment group scores were slightly higher than the control group.

Table 2. Change in TKAS-PFA scores in treatment and control groups pre-and post-professional development training.

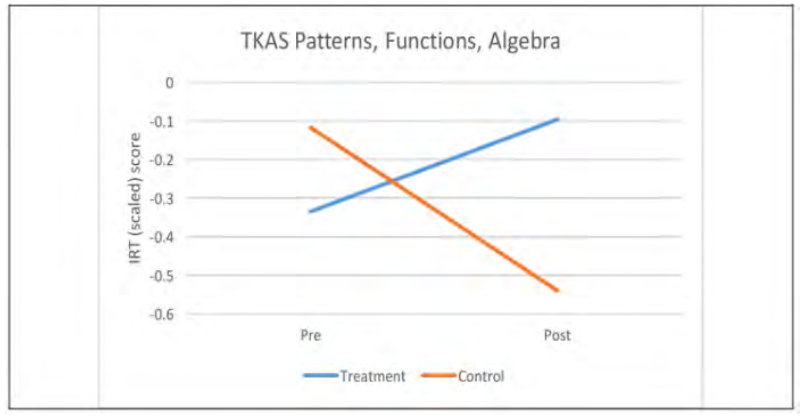

\section{Conclusion}

Results of this portion of the study demonstrate that teacher's content/pedagogical content knowledge in mathematics increased from pre-test to posttest among the teachers who were in the treatment group. The findings of this study support the conclusions made by Walker (2007) about rethinking professional development for elementary mathematics teachers.

\section{References}

D'Ambrosio, B. S., Boone, W. J., \& Harkness, S. S. (2004). Planning district-wide professional development: Insights gained from teachers and students regarding mathematics teaching in a large urban district. School Science and Mathematics, 104(1), 5-15.

Farmer, J. D., Gerretson, H., \& Lassak, M. (2003). What teachers take from professional development: Cases and implications. Journal of Mathematics Teacher Education, 6, 331-360.

Hill, H.C., Schilling, S.G., \& Ball, D.L. (2004). Developing measures of teachers' mathematics knowledge for teaching. Elementary School Journal, 105, 11-30.

Telese, J. A. (2012). Middle School Mathematics Teachers' Professional Development and Student Achievement. The Journal of Educational Research, 105, 102-111.

Walker, E. N. (2007). Rethinking professional development for elementary mathematics teachers. Teacher Education Quarterly, 34(3), 113-134. 